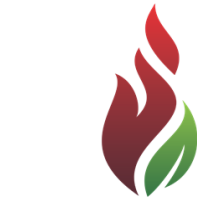

SUSTENERE

Publishing Corporation

\section{AVALIAÇÃO FÍSICO-QUÍMICA E ECOTOXICOLÓGICA DE EFLUENTES PROVENIENTES DE ESTAÇÕES DE TRATAMENTO DE ESGOTO}

\section{RESUMO}

A qualidade da água pode ser representada através de uma série de parâmetros que exprimem suas características químicas, físicas e biológicas e deve ser avaliada de acordo com o uso pretendido para a mesma. Considerada como uma ciência relativamente nova, a ecotoxicologia descreve o estudo científico dos efeitos nocivos ocasionados a organismos vivos que se encontram expostos a substâncias químicas potencialmente tóxicas liberadas no meio ambiente. No Brasil, a ecotoxicologia aquática tem sido utilizada há alguns anos como parâmetro de qualidade das águas, constituindo um importante instrumento no monitoramento dos recursos hídricos. O presente estudo teve o objetivo de avaliar, através da realização de análises físico-químicas e de ensaios ecotoxicológicos com os microcrustáceos Daphnia similis e Ceriodaphnia dubia, a qualidade dos efluentes provenientes das Estações de Tratamento de Esgoto (ETEs) dos municípios paulistas de São João da Boa Vista, Espírito Santo do Pinhal e Águas da Prata. Os efluentes foram coletados na entrada e na saída das estações e os parâmetros analisados foram DBO5 20, DQO, óleos e graxas, sólidos sedimentáveis, toxicidade aguda em D. similis e toxicidade crônica em C. dubia. As análises laboratoriais foram desempenhadas em laboratórios da Companhia Ambiental do Estado de São Paulo (CETESB). Os resultados encontrados mostraram que todos os parâmetros físico-químicos analisados nos efluentes das estações de tratamento atenderam aos padrões de lançamento estabelecidos pela legislação vigente. As eficiências dos tratamentos na remoção da carga orgânica foram de 95,9\%, 93,6\% e 75,7\%, para as ETEs de Espírito Santo do Pinhal, São João da Boa Vista e Águas da Prata, respectivamente.

PALAVRAS-CHAVES: Análises Físico-químicas; Efluentes; Ensaios Ecotoxicológicos.

\section{PHYSICOCHEMICAL AND ECOTOXICOLOGICAL EVALUATION OF EFFLUENTS FROM SEWAGE TREATMENT PLANTS}

\section{ABSTRACT}

The water quality can be represented through a series of parameters which express their chemical, physical and biological characteristics, and it must be evaluated in accordance with its intended use. Considered as a relatively new science, ecotoxicology describes the scientific study of the harmful effects caused to organisms that are exposed to potentially toxic chemical substances released into the environment. In Brazil, the aquatic ecotoxicology has been used for some years as a parameter of water quality, constituting an important tool in monitoring of water resources. The present study aimed to evaluate, through the realization of physicochemical analyses and ecotoxicological tests with microcrustaceans Daphnia similis and Ceriodaphnia dubia, the quality of effluents from Sewage Treatment Plants (STPs) of São João da Boa Vista, Espírito Santo do Pinhal and Águas da Prata, located in the State of São Paulo. The effluents were collected at the inlet and outlet of the Sewage Treatment Plants and the parameters analyzed were BOD5 20, COD, oils and greases, sedimentable solids, acute toxicity in D. similis and chronic toxicity in $\mathrm{C}$. dubia. The laboratory analyses were performed in the laboratories of the Environmental Company of the State of São Paulo (CETESB). The results showed that all physicochemical parameters analyzed in the effluents of the treatment plants complied with the discharge standards established by current legislation.

KEYWORDS: Ecotoxicological Tests; Effluents; Physicochemical Analyses
Revista Ibero-Americana de

Ciências Ambientais, Aquidabã, v.5, n.1, Dez 2013, Jan, Fev, Mar, Abr, Mai 2014.

ISSN 2179-6858

SECTION: Articles

TOPIC: Saneamento e Tratamento de Resíduos

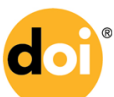

DOI: 10.6008/SPC2179-6858.2014.001.0022

Renan Destefano Tavares

Centro Regional Universitário Espírito Santo do Pinhal, Brasil http://lattes.cnpq.br/3997986023084549 redestefano@hotmail.com

Received: 12/03/2014

Approved: $31 / 05 / 2014$ Reviewed anonymously in the process of blind peer.

Referencing this:

TAVARES, R. D.. Avaliação físico-química e ecotoxicológica de efluentes provenientes de estações de tratamento de esgoto. Revista Ibero-Americana de Ciências Ambientais, Aquidabã, v.5, n.1, p.303-318, 2014. DOI: http://dx.doi.org/10.6008/SPC2179 6858.2014 .001 .0022 


\section{INTRODUÇÃO}

A água representa um elemento fundamental à sobrevivência de todas as formas de vida do planeta, constituindo um bem social primordial à adequada qualidade de vida do homem e um recurso indispensável para o desenvolvimento, equilíbrio e manutenção dos ecossistemas.

$\mathrm{Na}$ trajetória da evolução humana, os recursos naturais sofreram diversos efeitos em decorrência das intervenções antrópicas sobre o meio ambiente. Os ecossistemas aquáticos, por exemplo, têm sido há muito tempo alvos de contaminação ocasionada por despejos irregulares de substâncias que, quando lançadas, se distribuem e interagem com o meio, alteram suas características e produzem impactos muitas vezes irreversíveis.

A qualidade da água pode ser representada através de uma série de parâmetros que exprimem suas características químicas, físicas e biológicas e deve ser avaliada de acordo com o uso pretendido para a mesma. Segundo Von Sperling (1996), é muito importante que sejam estabelecidos padrões de qualidade da água embasados por suportes legais.

Com os avanços da ciência e da tecnologia, sistemas de tratamento de esgoto foram desenvolvidos com a finalidade de diminuir a carga poluidora dos efluentes e minimizar, principalmente, os impactos ocasionados aos recursos hídricos. No entanto, verifica-se que, em muitos casos, as tecnologias empregadas se mostram ineficientes quanto à remoção da toxicidade dos efluentes, o que afeta diretamente a biota do corpo receptor atingido.

Considerada como uma ciência relativamente nova, a ecotoxicologia descreve o estudo científico dos efeitos nocivos ocasionados a organismos vivos que se encontram expostos a substâncias químicas potencialmente tóxicas liberadas no meio ambiente, produzindo informações que permitem o reconhecimento sistemático das respostas dos ecossistemas em função das interações nele realizadas. No Brasil, a ecotoxicologia aquática tem sido utilizada há alguns anos como parâmetro de qualidade das águas, constituindo um importante instrumento do monitoramento dos recursos hídricos.

O objetivo do presente estudo foi avaliar, através da realização de análises físico-químicas e de ensaios ecotoxicológicos com os microcrustáceos Daphnia similis e Ceriodaphnia dubia, a qualidade dos efluentes provenientes das Estações de Tratamento de Esgoto (ETEs) dos municípios paulistas de São João da Boa Vista, Espírito Santo do Pinhal e Águas da Prata.

\section{REVISÃO TEÓRICA}

\section{Padrões de Qualidade da Água}

As características da água podem sofrer interferências decorrentes de fenômenos naturais ou da ação do homem que, de forma concentrada ou dispersa, contribui para a inserção de compostos que afetam sua qualidade (VON SPERLING, 1996). 
Entre os diversos usos da água estão o abastecimento doméstico, a irrigação, a dessedentação de animais, a preservação da flora e da fauna, a recreação e lazer, a navegação, a diluição de despejos e outros. Os usos estão diretamente relacionados à qualidade requerida para a água (VON SPERLING, 1996).

A qualidade de um ambiente aquático pode ser determinada tanto através de medições quantitativas, realizadas com a utilização de análises físicas e químicas ou por meio de testes biológicos e bioquímicos, como medições de $\mathrm{DBO}$, ensaios de toxicidade, entre outros, quanto através de medidas semiquantitativas e qualitativas, tais como índices bióticos, aspectos visuais, inventários de espécies e outros. O mesmo autor cita que um ambiente aquático pode ter sua qualidade definida segundo a presença de compostos orgânicos e inorgânicos em diferentes concentrações e especiações ou pela composição e estrutura da biota presente na água.

A Associação Brasileira de Normas Técnicas (ABNT, 1993) define que os padrões de qualidade da água são representados por meio de um conjunto de parâmetros e seus respectivos limites. Os padrões são estabelecidos com base em critérios científicos que representam os limites quantitativos fixados para um eventual parâmetro que, ao estar dentro dos valores máximos ou mínimos, conforme a natureza do constituinte, assegurarão os usos pretendidos para o recurso hídrico. Tais critérios permitem avaliar os riscos e os danos causados a uma determinada vítima em relação à exposição desta a uma dose conhecida do poluente analisado. Assim, o padrão de qualidade deve ser no mínimo igual ao critério de qualidade requerido para determinado uso, visando à garantia da disponibilidade do mesmo (NASCIMENTO \& VON SPERLING, 1998).

Segundo Von Sperling (1996), além dos requisitos de qualidade, há a necessidade do estabelecimento de padrões de qualidade embasados por suportes legais, de modo que os parâmetros sejam cumpridos pelas entidades envolvidas por força da legislação. Em termos práticos existem três tipos de padrões de qualidade da água de interesse direto dentro da Engenharia Ambiental, a saber: padrões de lançamento no corpo receptor, padrões de qualidade do corpo receptor e padrões de qualidade para determinado uso imediato (VON SPERLING, 1996).

\section{Parâmetros físico-químicos de qualidade da água}

Os parâmetros que representam a qualidade da água podem traduzir as suas principais características químicas, físicas e biológicas (VON SPERLING, 1996).

Para Philippi Jr. e Silveira (2005), no aspecto físico podem ser determinados parâmetros como temperatura, turbidez, sólidos (totais, suspensos e dissolvidos), condutividade e cor. Os mesmos autores indicam que em uma avaliação química podem ser consideradas espécies iônicas, compostos orgânicos naturais, compostos orgânicos sintéticos, pH, alcalinidade e dureza. 
Alguns dos principais parâmetros físicos e químicos estudados na avaliação de um efluente predominantemente doméstico, segundo Von Sperling (1996), são os sólidos, os indicadores de matéria orgânica (DBO, DQO e outros), o nitrogênio e o fósforo.

A associação do monitoramento físico-químico ao monitoramento biológico gera informações que são essenciais para o estabelecimento dos padrões de qualidade da água (DAMATO, 2001).

\section{Bioindicadores de Qualidade da Água}

Metodologias que empregam exclusivamente índices físicos e químicos em programas de monitoramento da água têm sido alvos de críticas por diversos pesquisadores que, com o intuito de obter uma abordagem mais ecossistêmica, apontam para a necessidade da aplicação de métodos biológicos nos estudos (KUHLMANN et al., 2001).

A avaliação comportamental dos poluentes no ambiente e o monitoramento de suas ações através da utilização de organismos vivos é um campo relativamente novo nas ciências ambientais, o qual recebe o nome de biomonitoramento ou bioindicação. O conceito de bioindicação é frequentemente utilizado para definir as reações de um sistema biológico diante de um fator ambiental antropogênico ou modificado antropicamente, dependente de uma variável temporal e manifestadas através de respostas mensuráveis (LIMA, 2001).

De acordo com Klumpp (2001), são chamados de bioindicadores as plantas e animais usados na bioindicação. "Bioindicadores são organismos ou comunidades que reagem a alterações ambientais modificando suas funções vitais e/ou sua composição química e com isso fornecem informações sobre a situação ambiental” (LIMA, 2001).

Os primeiros estudos científicos desenvolvidos para a determinação de indicadores biológicos de qualidade da água foram realizados por Kolkwitz e Marson, em 1909, com a utilização de bactérias, fungos e protozoários. Na década de 60 , espécies de outros grupos taxonômicos começaram a ser utilizadas (DAMATO, 2001; BUSS et al., 2003).

Para Kuhlmann et al. (2001), um bioindicador é considerado bom quando apresenta ampla distribuição geográfica e fácil amostragem, possibilitando a realização de estudos comparativos.

\section{Ecotoxicologia}

Considerada relativamente nova quando comparada a outras ciências, a ecotoxicologia alcançou reconhecimento mundial a partir dos anos 60 (ZAGATTO, 2006). Segundo Azevedo e Chasin (2003), a expressão Ecotoxicologia foi introduzida pelo professor e pesquisador francês René Truhaut no ano de 1969, em uma junção da denominação eco (do grego oikos, significado de casa, habitat, meio ambiente: ecologia) e da palavra toxicologia (ciência dos agentes tóxicos, dos venenos e da intoxicação).

Ecotoxicologia pode ser descrita como "a ciência que estuda os efeitos das substâncias naturais ou sintéticas sobre os organismos vivos, populações e comunidades, animais ou vegetais, terrestres ou 
aquáticos, que constituem a biosfera, incluindo assim a interação das substâncias com o meio nos quais os organismos vivem num contexto integrado" (ZAGATTO, 2006, p. 06).

A Ecotoxicologia está ligada aos efeitos tóxicos das substâncias químicas e dos agentes físicos sobre os organismos vivos, principalmente às populações e comunidades dentro de um ecossistema, incluindo os caminhos de transferência e as interações de tais elementos com o ambiente.

Continuamente o meio ambiente é carregado por compostos orgânicos estranhos, chamados de xenobióticos, que são liberados por comunidades urbanas ou provenientes de fontes industriais. Individualmente, tais substâncias podem não ter potencialidade para causar danos, porém suas interações com outros elementos podem promover consequências indesejáveis. Deste modo, a ecotoxicidade pode ser o resultado não somente da ação de um componente químico, mas sim da influência mútua que exercem as várias substâncias presentes em determinado meio (ZAGATTO, 2006; FERNICOLA et al., 2003).

Apesar de todo o conhecimento alcançado, hoje em dia a quantidade de agentes químicos existentes ainda é motivo de preocupação. Dos seis milhões de substâncias conhecidas, 63 mil são utilizadas cotidianamente pelo homem e, portanto, frequentemente encontradas no meio ambiente. Uma vez que as análises físico-químicas tradicionalmente utilizadas não permitem a distinção entre as substâncias que afetam os sistemas biológicos e as que se apresentam inertes no meio e que as análises químicas qualitativas e quantitativas não estimam os efeitos dos xenobióticos no ecossistema e, portanto, não possibilitam a avaliação dos riscos potenciais de tais contaminantes, é de grande importância a aplicação de testes ecotoxicológicos como uma forma de complementação das análises tradicionais e reconhecimento das respostas da biota às interações nela aplicadas (BERTOLETTI, 2001; COSTA et al., 2008).

$\mathrm{Na}$ avaliação ecotoxicológica é essencial o conhecimento das fontes de emissão, das transformações, difusões e dos destinos dos poluentes em determinado ambiente (ZAGATTO, 2006).

Zagatto (2006) descreve que durante reuniões do Committee of the International Council of Scientific Unions (ICSU), em Estolcomo, foram estabelecidos direcionamentos para os estudos ecotoxicológicos, os quais envolvem três sequências principais: i) Estudo da entrada dos poluentes no meio abiótico, distribuição e destino nos distintos compartimentos; ii) Estudo da entrada e destino dos xenobióticos nas cadeias biológicas e suas formas de transferência nos níveis tróficos; iii) Estudo qualitativo e quantitativo dos efeitos de toxicidade causados pelas substâncias no ecossistema com consequências ao homem (ZAGATTO, 2006).

De acordo com Fernicola; Bohrer-Morel; Bainy (2003), no Brasil, os ecossistemas aquáticos têm sido os mais estudados, com ênfase em estudos realizados em rios e córregos, lagos e represas e Estações de Tratamento de Esgoto. 


\section{Ensaios Ecotoxicológicos em Organismos Aquáticos}

A avaliação da toxicidade de agentes químicos por meio de ensaios ecotoxicológicos em ambientes aquáticos é realizada através da utilização de organismos representativos da coluna d'água ou dos sedimentos e os testes podem ser aplicados em campo ou em laboratório (ARAGÃO \& ARAÚJO, (2006); BERTOLETTI, 2001).

Os ensaios ecotoxicológicos tradicionais são usualmente desenvolvidos em laboratório e consistem na exposição de organismos previamente selecionados a distintas concentrações da amostra a ser testada em determinados períodos de tempo (ARAGÃO; ARAÚJO, 2006; BERTOLETTI, 2001). A Figura 01 ilustra um esquema representativo do ensaio de toxicidade realizada em laboratório.

Comumente, tais estudos são desenvolvidos com a utilização de testes simples, como os de exposição em curto prazo, para a avaliação de efeitos agudos, porém, conforme os objetivos e necessidades do trabalho, testes mais complexos podem ser aplicados, como os de longo prazo, que visam à avaliação de efeitos crônicos (ARAGÃO \& ARAÚJO, 2006; BERTOLETTI, 2001).

De acordo com Aragão e Araújo (2006), o ensaio de toxicidade aguda pode ser definido como aquele que avalia os efeitos severos e rápidos sofridos pelos organismos que se encontram em exposição a determinado agente químico em um período de tempo que varia, geralmente, de 24 a 96 horas. Os resultados das avaliações envolvem a determinação de uma CL50 (concentração letal média) ou de uma CE50 (concentração efetiva média), que representam a concentração do agente tóxico capaz de causar a 50\% dos organismos-teste, após determinado período de exposição, efeitos de letalidade ou de imobilidade, respectivamente. Quanto menor é a CL50 ou a CE50, mais tóxica é a amostra (MAGALHÃES \& FERRÃO FILHO, 2008).

Os ensaios de toxicidade crônica, de um modo geral, avaliam a ação dos poluentes através de resultados que se traduzem a partir de efeitos subletais causados aos organismosteste, como por exemplo, disfunções biológicas no crescimento, reprodução, desenvolvimento de ovos e etc. Os resultados são expressos na forma de uma Concentração de Efeito Não Observado (CENO), que representa a concentração segura do agente tóxico a ser lançado no corpo d'água (MAGALHÃES \& FERRÃO FILHO, 2008).

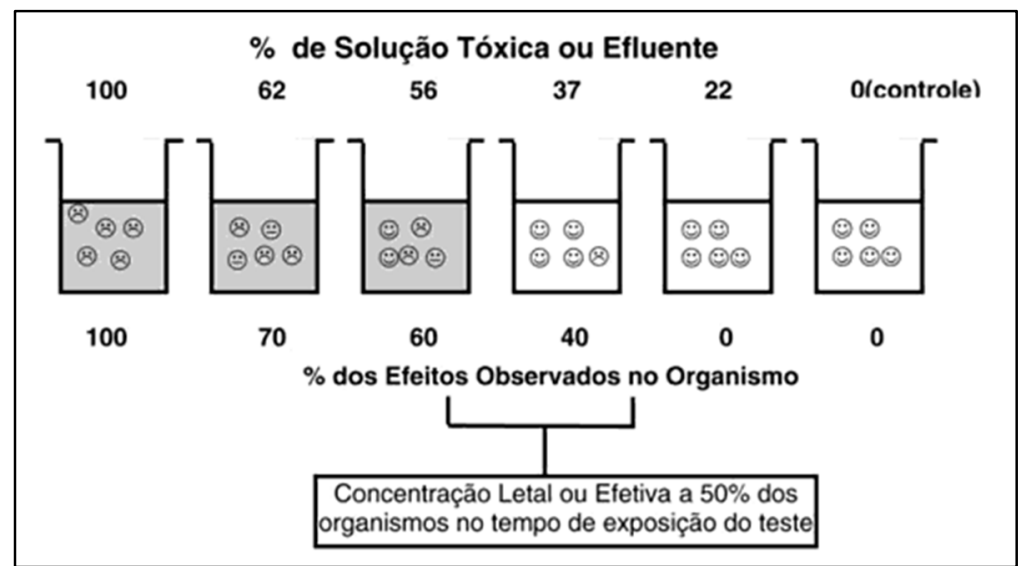

Figura 01: Esquema básico do teste de toxicidade. Fonte: Valentim \& Dezotti (2008). 
$\mathrm{Na}$ avaliação toxicológica de um efluente é recomendado o uso de organismos pertencentes, no mínimo, a três níveis tróficos como, por exemplo, peixes, microcrustáceos e microrganismos (VALENTIM \& DEZOTTI, 2008).

Por estabelecerem um importante elo entre os níveis inferiores e superiores da cadeia alimentar e por se apresentarem como consumidores primários e secundários no ecossistema aquático, microcrustáceos dos gêneros Daphnia e Ceriodaphnia, conhecidos popularmente como pulgas d'água, constituem importantes indicadores biológicos em estudos de controle da qualidade da água e em bioensaios para a determinação da toxicidade de efluentes, metais pesados e inseticidas, possuindo um tamanho que varia de 0,5 a $3,0 \mathrm{~mm}$ e ampla distribuição geográfica (VALENTIM \& DEZOTTI, 2008).

\section{A Toxicidade dos Efluentes Sanitários}

Os contaminantes orgânicos e inorgânicos que atingem as Estações de Tratamento de Esgoto representam um fator de grande interesse tanto para o tratamento em si, quanto para o corpo receptor atingido, que pode ter sua biodiversidade impactada pela ocorrência de eventos indesejados como excesso de nutrientes, ausência de oxigênio, incapacidade de alimentação e reprodução dos organismos ou decorrente dos próprios efeitos tóxicos de tais substâncias (HAMADA, 2008).

Entre os componentes tóxicos que podem estar contidos nas águas residuais estão a amônia não ionizada, os cianetos, os sulfetos, o cloro, as cloraminas, os fenóis, os surfactantes aniônicos, os metais pesados e uma grande diversidade de compostos orgânicos (SINGLETON, 1980).

Segundo Hamada (2008), compostos tóxicos como os detergentes ou surfactantes, por exemplo, estão presentes nas Estações de Tratamento de Esgoto em concentrações importantes que variam de 3 a 10 ppm.

Godoy (2007) destaca que os sistemas de tratamento compostos por lagoas de estabilização, amplamente utilizados devido ao baixo custo de instalação e simplicidade operacional, podem, em condições específicas, proporcionar ambientes favoráveis à proliferação de cianobactérias, as quais são capazes de produzir toxinas bioacumulativas e causar diferentes sintomas de intoxicação.

A cloração está entre os métodos de desinfecção mais utilizados no tratamento dos efluentes sanitários (HAMADA, 2008). Segundo Von Sperling (1996), a desvantagem deste processo consiste na formação de compostos organoclorados carcinogênicos, como os trialometanos, e de cloraminas, que se formam a partir da matéria orgânica presente na água.

De acordo com Bertoletti (2001), uma vez que os efluentes líquidos são, normalmente, constituídos por uma grande variedade de substâncias, cuja interação pode causar efeitos tóxicos raramente previsíveis através de análises químicas, a avaliação do risco ecotoxicológico se torna fundamental. Assim, a partir dos resultados obtidos nos bioensaios de toxicidade e do 
conhecimento da vazão do efluente e do corpo receptor, é possível realizar um estudo estimado do impacto que tais despejos podem causar ao ecossistema aquático com a utilização de relações matemáticas, conforme proposto por Bertoletti (2001) e pela Resolução CONAMA n 430 de 2011, que complementa e altera a Resolução CONAMA n 357 de 2005 (CONAMA, 2011), em que:

$$
\text { C.E.C. } R \leq \frac{C E 50}{10} \quad \text { C.E.C.R } \leq \text { CENO }
$$

Em que, CECR representa a Concentração do Efluente no Corpo Receptor, dada pela Equação 01 (CONAMA, 2011); CE50, a Concentração Efetiva Mediana (resultado do teste de toxicidade aguda); CENO, a Concentração de Efeito Não Observado (resultado do teste de toxicidade crônica) e Divisor 10, o fator de aplicação para prevenir efeito crônico.

$$
\text { C.E.C.R }=\frac{\text { Vazão do efluente } x 100}{\text { Vazão do efluente }+ \text { Vazão do corpo receptor }}
$$

\section{METODOLOGIA}

\section{Áreas de Estudo}

Situados na divisa com Minas Gerais, os municípios de Águas da Prata, Espírito Santo do Pinhal e São João da Boa Vista se localizam na região leste do Estado de São Paulo e estão interligados pela Rodovia Governador Doutor Adhemar Pereira de Barros, SP-342, que se inicia em Mogi-Guaçu, SP, e se encerra na divisa com Poços de Caldas, MG.

A Tabela 01 apresenta as principais características geográficas, demográficas, climatológicas e socioeconômicas dos três municípios circunvizinhos.

Tabela 01: Características dos municípios.

\begin{tabular}{c|c|c|c|c}
\hline & Unidade & $\begin{array}{c}\text { Águas da } \\
\text { Prata }\end{array}$ & $\begin{array}{c}\text { Espírito Santo do } \\
\text { Pinhal }\end{array}$ & $\begin{array}{c}\text { São João da Boa } \\
\text { Vista }\end{array}$ \\
\hline População $^{1}$ & habitantes & 7.584 & 41.907 & 83.639 \\
\hline Área da unidade territorial $^{1}$ & $\mathrm{~km}^{2}$ & 142,96 & 389,42 & 516,41 \\
\hline Densidade demográfica & & 161,96 \\
\hline IDH $^{2}$ & $\mathrm{hab}^{2} \mathrm{~km}^{2}$ & 53,05 & 107,61 & 0,840 \\
\hline $\begin{array}{c}\text { Classificação climática de } \\
\text { Köppen }\end{array}$ & - & 0,810 & 0,808 & Cwa \\
\hline Índice pluviométrico anual $^{3}$ & - & $\mathrm{Cwa}$ & Cwa & 1494,7 \\
\hline
\end{tabular}

Fontes: ${ }^{1}$ IBGE (2010); ${ }^{2}$ PNUD (2000); ${ }^{3}$ CEPAGRI (s.d).

A Companhia de Saneamento Básico do Estado de São Paulo (SABESP) é a empresa responsável pela coleta e tratamento dos esgotamentos sanitários gerados em tais municípios.

Os estudos aqui apresentados foram realizados com os efluentes tratados pelas Estações de Tratamento de Esgoto operadas pela SABESP que, respectivamente, para Águas da Prata, Espírito Santo do Pinhal e São João da Boa Vista, possuem as seguintes coordenadas UTM, WGS84, zona 23 k: 321.625,84 m E e 7.571.780,12 m N; 316.133,93 m E e 7.541.931,00 m N; 312.959,74 m E e 7.572.477,79 m N.

As três ETEs operam sistemas constituídos por lagoas de estabilização. No município de Águas da Prata o tratamento se desenvolve em um sistema composto por lagoa facultativa, com a Estação situada no final da Avenida Eduardo Lírio, no bairro Jardim Anunziato. Em Espírito Santo 
do Pinhal o tratamento é realizado em lagoa anaeróbia seguida por lagoa facultativa, com a ETE localizada na Rodovia SP-342, que liga o município à Mogi-Guaçu, aproximadamente no quilômetro 196 e, em São João da Boa Vista, os efluentes sanitários são tratados através de um sistema constituído por duas lagoas aeradas de mistura completa seguidas por duas lagoas de decantação, com o empreendimento instalado na antiga Estrada São João da Boa Vista à Vargem Grande do Sul, aproximadamente no quilômetro 02.

As dimensões e operações unitárias variam de uma unidade para a outra, entretanto, os três sistemas são compostos pelas etapas de gradeamento, medição da vazão de entrada, desarenação, tratamento biológico, desinfecção e medição da vazão de saída.

\section{Coleta dos Efluentes}

A campanha de amostragem dos efluentes nas Estações de Tratamento de Esgoto dos municípios de Águas da Prata, Espírito Santo do Pinhal e São João da Boa Vista compreendeu, respectivamente, as datas de 08, 15 e 22 de maio. Em todas as ocasiões houve 0 acompanhamento de funcionários da SABESP.

No dia anterior ao programado para cada coleta foram realizadas a separação e a identificação de toda a frascaria utilizada. O procedimento consistiu em efetuar, em todos os frascos, a marcação do número de controle estabelecido pelo laboratório, do local da coleta, do ponto de amostragem e do parâmetro de qualidade a ser analisado.

A distribuição dos recipientes em relação aos parâmetros foi realizada de acordo com orientações do laboratório, conforme apresentado no Quadro 01.

Todos os frascos vedados foram armazenados em caixas de isopor para a locomoção dos mesmos até os locais de coleta.

Quadro 01: Frascaria referente aos parâmetros analisados.

\begin{tabular}{|c|c|}
\hline Frasco de polietileno $-500 \mathrm{ml}$ & DQO \\
\hline Frasco de polietileno $-1000 \mathrm{ml}$ & $\begin{array}{c}\text { Sólidos sedimentáveis, Toxicidade aguda em D. similis e } \\
\text { Toxicidade crônica em C. dubia }\end{array}$ \\
\hline Frasco de polietileno $-1500 \mathrm{ml}$ & DBO5 20 \\
\hline Frasco de vidro cor âmbar de boca larga & Óleos e Graxas \\
\hline
\end{tabular}

Os efluentes foram coletados na entrada e na saída das Estações de Tratamento. Para o desempenho das coletas foram antecipadamente separados os frascos referentes ao ponto de amostragem em questão. O Quadro 02 apresenta os parâmetros e seus respectivos pontos de amostragem.

Quadro 02: Parâmetros analisados em relação aos pontos de amostragem.

\begin{tabular}{|c|c|}
\hline Entrada da ETE & $\mathrm{DBO}_{520}$ e DQO \\
\hline Saída da ETE & $\begin{array}{c}\mathrm{DBO}_{5} 20, \mathrm{DQO}, \text { Óleos e Graxas e Sólidos sedimentáveis, } \\
\text { Toxicidade aguda em D. similis e Toxicidade crônica em C. dubia }\end{array}$ \\
\hline
\end{tabular}


Com a frascaria preparada e a utilização de luvas descartáveis, os efluentes foram coletados nos pontos especificados com o auxílio de um balde de aço inoxidável suspenso a uma corda.

Em todos os pontos de amostragem foi efetuada a aferição da temperatura ambiente com um termômetro de laboratório e, com a utilização de um pHmetro, foi procedida a medição da temperatura e do $\mathrm{pH}$ do efluente. Os dados foram anotados em uma planilha juntamente com a indicação da sua cor aparente e a descrição "sim" ou "não" para a ocorrência de chuva nas últimas 24 horas, informações importantes para a realização das análises.

Os efluentes coletados foram inseridos nos seus respectivos frascos juntamente com os reagentes especificados pelo laboratório para a conservação da amostra, os quais tiveram suas dosagens mensuradas a partir do valor do $\mathrm{pH}$ do efluente, medido através de tiras indicadoras de $\mathrm{pH}$. Os frascos referentes às análises ecotoxicológicas foram totalmente preenchidos com a amostra, de modo a evitar a presença de ar no interior dos mesmos. O Quadro 03 apresenta os parâmetros analisados e as formas de conservação referentes a cada um. Os frascos devidamente preenchidos foram vedados e armazenados em um cooler com gelo.

Quadro 03: Parâmetros analisados e suas respectivas formas de conservação.

\begin{tabular}{|c|c|}
\hline $\mathrm{DBO}_{5} \mathbf{2 0}$ & Refrigeração \\
\hline $\mathrm{DQO}$ & Ácido sulfúrico até pH < 2 + Refrigeração \\
\hline Óleos e graxas & Ácido clorídrico até pH < 2 + Refrigeração \\
\hline Sólidos sedimentáveis & Refrigeração \\
\hline Toxicidade aguda e crônica & Refrigeração \\
\hline
\end{tabular}

No intervalo entre as coletas, o eletrodo do pHmetro foi devidamente limpo com um esguicho de água destilada proporcionado por uma pisseta. Após a execução de todas as amostragens, um recipiente com glicerina foi alocado juntamente com a frascaria dentro do cooler como indicador da temperatura de armazenamento.

\section{Análises Laboratoriais}

As análises laboratoriais foram realizadas pelos laboratórios da Companhia Ambiental do Estado de São Paulo (CETESB). Foram encaminhadas ao Setor de Ecotoxicologia Aquática, em São Paulo, as amostragens referentes aos estudos ecotoxicológicos e ao Setor de Laboratório de Ribeirão Preto, as amostras referentes às análises dos parâmetros físico-químicos.

\section{RESULTADOS E DISCUSSÃO}

\section{Análises Físico-Químicas}


Os resultados referentes às análises físico-químicas realizadas nos afluentes e efluentes das Estações de Tratamento de Esgoto estão apresentados nas Tabelas 02 e 03, respectivamente.

Tabela 02: Parâmetros físico-químicos dos afluentes das ETEs.

\begin{tabular}{c|c|c|c|c}
\hline Parâmetro & Unidade & Águas da Prata & Espírito Santo do Pinhal & São João da Boa Vista \\
\hline $\mathrm{DBO}_{52} \mathbf{m}$ & $\mathrm{mg} / \mathrm{L} \mathrm{de} \mathrm{O}_{2}$ & 169 & 339 & 761 \\
$\mathrm{DQO}$ & $\mathrm{mg} / \mathrm{L} \mathrm{de} \mathrm{O} \mathrm{O}_{2}$ & 423 & 612 & $3,58 \times 10^{3}$ \\
\hline
\end{tabular}

Tabela 03: Parâmetros físico-químicos dos efluentes das ETEs.

\begin{tabular}{|c|c|c|c|c|c|}
\hline Parâmetro & Unidade & $\begin{array}{c}\text { Águas da } \\
\text { Prata }\end{array}$ & $\begin{array}{c}\begin{array}{c}\text { Espírito Santo do } \\
\text { Pinhal }\end{array} \\
\end{array}$ & $\begin{array}{c}\text { São João da Boa } \\
\text { Vista }\end{array}$ & $\begin{array}{c}\text { CONAMA } n^{\circ} \\
430 / 2011\end{array}$ \\
\hline $\mathrm{DBO}_{5} 20$ & $\begin{array}{c}\mathrm{mg} / \mathrm{L} \mathrm{de} \\
\mathrm{O}_{2}\end{array}$ & 41 & 14 & 49 & 120 \\
\hline DQO & $\mathrm{mg} / \mathrm{L} \mathrm{de}$ & 170 & 87 & 190 & - \\
\hline Óleos e graxas & $\mathrm{mg} / \mathrm{L}$ & 18 & 22 & 15 & $<100$ \\
\hline $\begin{array}{l}\text { Sollidos } \\
\text { sedimentáveis }\end{array}$ & $\mathrm{mL} / \mathrm{L}$ & $<0,1$ & 0,4 & 0,1 & $<1$ \\
\hline
\end{tabular}

Com os valores da Demanda Bioquímica de Oxigênio $\left(\mathrm{DBO}_{5} 20\right)$ encontrados na entrada e na saída dos efluentes das estações, é possível realizar o cálculo das eficiências dos tratamentos na remoção da matéria orgânica biodegradável. A Tabela 04 traz as eficiências das Estações de Tratamento de Esgoto amostradas.

Tabela 04: Eficiências das ETEs na remoção da $\mathrm{DBO}_{5} 20$

\begin{tabular}{c|c|c}
\hline ETE & Unidade & Eficiência \\
\hline Águas da Prata & $\%$ & 75,7 \\
Espírito Santo do Pinhal & $\%$ & 95,9 \\
São João da Boa Vista & $\%$ & 93,6 \\
\hline
\end{tabular}

A alínea "d", inciso I, art. 21 da Resolução n 430 de 2011 do Conselho Nacional de Meio Ambiente estabelece o limite máximo da $\mathrm{DBO}_{5} 20$ permitido para o lançamento direto de efluentes oriundos de sistemas de tratamento de esgotos sanitários em cursos d'água.

d) Demanda Bioquímica de Oxigênio - DBO 5 dias, $20^{\circ} \mathrm{C}$ : máximo de $120 \mathrm{mg} / \mathrm{L}$, sendo que este limite somente poderá ser ultrapassado no caso de efluente de sistema de tratamento com eficiência de remoção mínima de $60 \%$ de DBO, ou mediante estudo de autodepuração do corpo hídrico que comprove atendimento às metas do enquadramento do corpo receptor (CONAMA, 2011).

No que tange à remoção da carga orgânica dos efluentes pelos sistemas de tratamento empregados, verifica-se que tanto os resultados quantitativos encontrados através das análises físico-químicas quanto as eficiências calculadas para as estações de tratamento atendem à citada legislação.

Ao realizar um comparativo dos mesmos resultados com a literatura, observa-se que as eficiências das ETEs dos municípios de São João da Boa Vista e Espírito Santo do Pinhal, as quais se apresentaram, respectivamente, com valores de 93,6\% e 95,9\%, mostraram resultados melhores que os esperados, considerando que, segundo Von Sperling (1996), os sistemas de tratamento que operam lagoas anaeróbias seguidas por lagoas facultativas e os que operam 
lagoas aeradas de mistura completa seguidas por lagoas de decantação possuem eficiência da ordem de 70 a $90 \%$.

O mesmo autor cita que a relação $\mathrm{DQO} / \mathrm{DBO}_{5} 20$ para esgotos domésticos brutos varia de 1,7 a 2,4. A Tabela 05 apresenta a relação $\mathrm{DQO} / \mathrm{DBO}_{5} 20$ dos afluentes analisados.

Tabela 05: Relação $\mathrm{DQO} / \mathrm{DBO}_{5} 20$ dos esgotos sanitários brutos das ETEs.

\begin{tabular}{c|c}
\hline ETE & $D Q O / D B O_{520}$ \\
\hline Águas da Prata & 2,5 \\
Espírito Santo do Pinhal & 1,8 \\
São João da Boa Vista & 4,7 \\
\hline
\end{tabular}

Como pode ser observada na Tabela 05 , a relação $\mathrm{DQO} \mathrm{DBO}_{5} 20$ encontrada para o afluente da unidade de tratamento do município de São João da Boa Vista apresentou-se muito elevada em relação à faixa proposta na literatura. Segundo Von Sperling (1996), tal resultado aponta para o recebimento de uma alta fração não biodegradável pela estação de tratamento, cabendo avaliar se tais elementos são importantes em termos de poluição do corpo receptor ou não, para que sejam empregados métodos de tratamento físico-químicos ou biológicos. É provável que esta causa seja decorrente do lançamento de efluentes de origem industrial na rede de coleta de esgoto do município. Visto que apenas uma amostragem foi realizada, não é possível avaliar a frequência com que efluentes com tais características chegam à unidade de tratamento. Contudo, considerando que a eficiência do tratamento na remoção da $\mathrm{DBO}_{5} 20$ do efluente não foi comprometida, é possível afirmar que tal fração não biodegradável não tem causado efeitos nocivos aos organismos que desempenham o tratamento biológico na unidade, o que não descarta, entretanto, a existência do risco ecotoxicológico decorrente do lançamento de tais constituintes no curso d'água receptor.

Como podem ser observados na Tabela 03, os resultados analíticos obtidos para os parâmetros sólidos sedimentáveis e óleos e graxas dos efluentes provenientes das três ETEs também atenderam aos limites estabelecidos pela legislação aplicada, o que demonstra o bom desempenho dos tratamentos na remoção de tais componentes.

\section{Ensaios Ecotoxicológicos}

As Tabelas 06 e 07 apresentam os resultados referentes aos ensaios ecotoxicológicos desenvolvidos com os microcrustáceos Daphnia similis e Ceriodaphnia dubia, para a verificação de efeitos agudos e crônicos, respectivamente, nos efluentes das Estações de Tratamento de Esgoto.

Tabela 06: Resultados dos testes de toxicidade aguda realizados em Daphnia similis.

\begin{tabular}{c|cc}
\hline ETE & Unidade & CE(I)50; 48 $\boldsymbol{h}^{*}$ \\
\hline Águas da Prata & $\%$ & $>90$ \\
Espírito Santo do Pinhal & $\%$ & $>96$ \\
São João da Boa Vista & $\%$ & $>96$ \\
\hline
\end{tabular}

Nota: * Concentração nominal da amostra, no início do ensaio, que causa imobilidade a $50 \%$ dos organismos-teste em 48 horas de exposição.

Tabela 07: Resultados dos testes de toxicidade crônica realizados em Ceriodaphnia dúbia. 


\begin{tabular}{c|cc}
\hline ETE & Unidade & CENO(I) $^{*}$ \\
\hline Águas da Prata & $\%$ & $<6$ \\
Espírito Santo do Pinhal & $\%$ & 25 \\
São João da Boa Vista & $\%$ & 25 \\
\hline
\end{tabular}

Nota: * Maior concentração nominal da amostra, no início do ensaio, que não causa efeito tóxico na sobrevivência e reprodução dos organismos-teste em 7 dias de exposição.

A partir dos resultados obtidos nos bioensaios de toxicidade e do conhecimento da vazão do efluente e do corpo receptor, é possível realizar o estudo estimado do impacto que tais despejos podem causar ao ecossistema aquático, com a utilização de expressões matemáticas, conforme apresentado na Equação 01.

$$
C . E . C . R=\frac{\text { Vazão do efluente } x 100}{\text { Vazão do efluente }+ \text { Vazão do corpo receptor }}
$$

A Tabela 08 apresenta as vazões de lançamento dos efluentes das ETEs nos cursos d'água e as vazões mínimas de 7 dias consecutivos e período de retorno de 10 anos $\left(Q_{7,10}\right)$ dos seus respectivos corpos receptores.

Tabela 08: Vazões de lançamento das ETEs e respectivas $Q_{7,10}$ dos cursos d'água

\begin{tabular}{c|c|c|c}
\hline ETE & Unidade & $\begin{array}{c}\text { Vazão de lançamento no } \\
\text { corpo receptor }\end{array}$ & Q $_{7,10}$ do corpo receptor \\
\hline Águas da Prata & L/s & 8,0 & 139,3 \\
Espírito Santo do Pinhal & L/s & 54,0 & 190,0 \\
São João da Boa Vista & L/s & 100,0 & 3722,0 \\
\hline
\end{tabular}

Fonte: SABESP, 2013.

Com os dados apresentados e através da Equação 01, é possível determinar a Concentração do Efluente no Corpo Receptor (CECR). A Tabela 09 traz os valores das CECRs obtidas para cada ETE.

Tabela 09: Concentrações dos Efluentes nos Corpos Receptores

\begin{tabular}{c|c|c}
\hline ETE & Unidade & CECR \\
\hline Águas da Prata & $\%$ & 5,43 \\
Espírito Santo do Pinhal & $\%$ & 22,13 \\
São João da Boa Vista & $\%$ & 2,62 \\
\hline
\end{tabular}

As alíneas "a" e "b", inciso I, art. 18 da Resolução CONAMA n 430 de 2011 estabelecem as relações que os resultados dos ensaios ecotoxicológicos devem ter com as concentrações do efluente nos seus respectivos cursos d'água receptores para que não possuam potencialidade para gerar efeitos adversos aos organismos aquáticos.

a) CECR deve ser menor ou igual a CENO quando for realizado teste de ecotoxicidade para medir o efeito tóxico crônico; ou b) CECR deve ser menor ou igual ao valor da Concentração Letal Mediana (CL50) dividida por 10; ou menor ou igual a 30 dividido pelo Fator de Toxicidade (FT) quando for realizado teste de ecotoxicidade para medir o efeito tóxico agudo (CONAMA, 2011).

Através dos resultados encontrados para as $\mathrm{CEs}(50)$, verifica-se que os efluentes analisados não apresentaram grande potencialidade para ocasionar efeitos tóxicos agudos ao 
microcrustáceo Daphnia similis, visto que os valores obtidos se mantiveram próximos à concentração de 100\% (concentração máxima). De acordo com Bertoletti (2013), o efluente é isento de toxicidade quando a $\mathrm{CE}(50)$ resultante se apresenta maior que $100 \%$. Deste modo, pode-se afirmar que os efluentes revelam, caso existente, uma toxicidade muito baixa.

Mediante a não determinação da Concentração Efetiva Mediana exata dos efluentes, não foi possível realizar a avaliação do risco ecotoxicológico em que estão submetidos os ecossistemas aquáticos dos seus respectivos corpos receptores por meio da aplicação das relações matemáticas propostas pela legislação, porém, ao considerar a diluição que tais despejos sofrem ao entrar em contato com os cursos d'água, é possível que, nestas características, não sejam ocasionados danos aos organismos que nele habitam. De acordo com a literatura, entre os efeitos tóxicos agudos que podem acometer os organismos aquáticos estão a imobilidade e a letalidade (MAGALHÃES \& FERRÃO FILHO, 2008).

Quanto aos resultados obtidos através das análises ecotoxicológicas desenvolvidas nos efluentes para verificar efeitos crônicos, observa-se que as ETEs dos municípios de São João da Boa Vista e de Espírito Santo do Pinhal atenderam ao preconizado pela legislação, ou seja, as CECRs encontradas se mantiveram inferiores às CENOs, concentrações dos efluentes que não causam efeito observável. Deste modo, pode-se afirmar que os efluentes das duas ETEs não oferecem riscos ecotoxicológicos aos seus respectivos corpos receptores.

Considerando que a CENO representa uma concentração segura, na qual o agente tóxico pode ser lançado no corpo receptor sem ocasionar danos aos organismos, verifica-se um cenário preocupante quanto ao resultado obtido para o efluente da ETE do município de Águas da Prata (<6\%). Como não houve definição experimental suficiente na porcentagem da concentração, não foi possível aplicar as relações matemáticas propostas na legislação e, consequentemente, desempenhar a avaliação do risco ecotoxicológico que o efluente apresenta, embora este seja eminente. Caso fosse efetuada a repetição do ensaio a fim de aumentar o número de diluições e determinar mais precisamente o valor da CENO, esta possivelmente se apresentaria inferior à CECR obtida $(5,43 \%)$ e, de tal modo, desacordar do estabelecido pela legislação.

\section{CONCLUSÕES}

As análises realizadas nos efluentes provenientes das Estações de Tratamento de Esgoto permitiram constatar que os sistemas de tratamento empregados nas três unidades operam com eficiência no que diz respeito à remoção da carga orgânica biodegradável, atendendo aos limites constantes na legislação vigente.

A partir das relações DBO/DQO efetuadas nos efluentes, verificou-se que a unidade de tratamento do município de São João da Boa Vista tem recebido a contribuição de efluentes com alta fração não biodegradável em sua rede de coleta, possivelmente de origem industrial. A complementação das análises físico-químicas tradicionais com os testes de ecotoxicidade permitiu 
a avaliação do risco ecotoxicológico que tais substâncias recalcitrantes oferecem. Deste modo, foi possível comprovar que nas condições analisadas o efluente não apresenta potencialidade para ocasionar efeitos adversos aos organismos aquáticos do corpo receptor.

Com relação às análises ecotoxicológicas realizadas no efluente da Estação de Tratamento de Esgoto do município de Espírito Santo do Pinhal, verificou-se o atendimento ao disposto na legislação. A CENO obtida se manteve inferior à CECR calculada, ou seja, o efluente se mostrou incapaz de proporcionar risco ecotoxicológico ao curso d'água em que é lançado.

Tendo em vista a inviabilidade da aplicação das relações matemáticas propostas na legislação para a consequente avaliação do risco ecotoxicológico que o efluente proveniente da ETE de Águas da Prata apresenta, devido à definição da sua CENO, espera-se que o presente estudo sirva de base para futuras pesquisas que visem à avaliação ecotoxicológica da qualidade do efluente tratado na referida unidade.

\section{AGRADECIMENTOS}

À Companhia Ambiental do Estado de São Paulo (CETESB), pela oportunidade e apoio, em especial ao Dr. Eng. Edinan Augusto Borsatto, pela atenção e incentivo dados desde o início da pesquisa; à Professora M.Sc. Ursula Luana Rochetto, pela orientação e dedicação; à Professora Dra. Marianna Stella Zibordi, pelo acompanhamento e cuidado dado ao trabalho; à minha família, pelo apoio e paciência, principalmente nos momentos de dificuldade; e à todos aqueles que de alguma forma contribuíram para a realização deste, meus sinceros agradecimentos.

\section{REFERÊNCIAS}

ABNT. NBR 9896:1993 - Glossário de Poluição das Águas. Rio de Janeiro, 1993.

ARAGÃO, M. A.; ARAÚJO, R. P. A.. Métodos de ensaios de toxicidade com organismos aquáticos. In: ZAGATTO, P. A.; BERTOLETTI, E.. Ecotoxicologia Aquática - Princípios e Aplicações. São Carlos: Rima, 2006.

AZEVEDO, F. A.; CHASIN, A. A. M.. As bases toxicológicas da ecotoxicologia. São Carlos: Rima, 2003. BERTOLETTI, E.. Controle Ecotoxicológico de efluentes líquidos no estado de São Paulo. 2 ed. São Paulo: CETESB, 2013.

BERTOLETTI, E.. Ecotoxicologia aquática. In: MAIA, N. B., MARTOS, H. L., BARRELLA, W.. Indicadores ambientais: conceitos e aplicações. São Paulo: EDUC/COMPED/INEP, 2001.

CONAMA. Resolução 430 de 13 de maio de 2011.

BUSS, D. F.; BAPTISTA, D. F.; NESSIMIAN, J. L.. Bases conceituais para a aplicação de biomonitoramento em programas de avaliação da qualidade da água de rios. Cad. Saúde Pública, Rio de Janeiro, v.19, n.2, p.465-473, 2003.

CEPAGRI. Clima dos Municípios Paulistas: Águas da Prata. 
CEPAGRI. Clima dos Municípios Paulistas: Espírito Santo do Pinhal.

CEPAGRI. Clima dos Municípios Paulistas: São João da Boa Vista.

COSTA, C. R.; OLIVI, P.; BOTTA, C. M. R.; ESPINDOLA, E. L. G.. A toxicidade em ambientes aquáticos: discussão e métodos de avaliação. Química Nova, v.31, n.7, p.1820-1830, 2008.

DAMATO, M.. O emprego de indicadores biológicos na determinação de poluentes orgânicos perigosos. In: MAIA, N. B., MARTOS, H. L., BARRELLA, W.. Indicadores ambientais: conceitos e aplicações. São Paulo: EDUC/COMPED/INEP, 2001.

FERNICOLA, N. A. G. G.; BOHRER-MOREL, M. B. C.; BAINY, A. C. D.. Ecotoxicologia. In: AZEVEDO, F. A.; CHASIN, A. A. M.. As bases toxicológicas da ecotoxicologia. São Carlos: Rima, 2003.

GODOY, O. A.. Avaliação da presença de cianobactérias em efluentes e sistema de tratamento de esgotos sanitários por lagoas de estabilização associadas a tratamento físico-químico. Dissertação (Mestrado) - Escola Politécnica da Universidade de São Paulo, 2007.

HAMADA, N.. Ensaios de toxicidade empregados na avaliação de efeitos no sistema de tratamento de esgoto e efluentes, ETE Suzano, e seu entorno, utilizando organismos aquáticos. Dissertação (Mestrado) - Instituto de Pesquisas Energéticas e Nucleares, 2008.

IBGE. População residente, total, urbana total e urbana na sede municipal, com indicação da área total e densidade demográfica segundo as Unidades da Federação e os municípios, 2010.

KLUMPP, A.. Utilização de bioindicadores de poluição em condições temperadas e tropicais. In: MAIA, N. B., MARTOS, H. L., BARRELLA, W.. Indicadores ambientais: conceitos e aplicações. São Paulo: EDUC/COMPED/INEP, 2001.

KUHLMANN, M. L. ; BRANDIMARTE, A. L. ; SHIMIZU, G. Y. ; ANAYA, M.. Invertebrados bentônicos como indicadores de impactos antrópicos sobre ecossistemas aquáticos continentais. . In: Nilson Borlina Maia; Henry L. Martos; Walter Barrella.. Indicadores ambientais: conceitos e aplicações. São Paulo:

EDUC/COMPED/INEP, 2001.

LIMA, J. S.. Processos biológicos e o biomonitoramento: aspectos bioquímicos e morfológicos. In: MAIA, N. B., MARTOS, H. L., BARRELLA, W.. Indicadores ambientais: conceitos e aplicações. São Paulo: EDUC/COMPED/INEP, 2001.

MAGALHÃES, D. P.; FERRÃO FILHO, A. S.. A Ecotoxicologia como ferramenta no biomonitoramento de ecossistemas aquáticos. Oecol. Bras., v.12, n.3, p.355-381, 2008.

NASCIMENTO, L. V.; VON SPERLING, M.. Os padrões brasileiros de qualidade das águas e os critérios para proteção da vida aquática, saúde humana e animal. In: Asociación Peruana de Ingeniería Sanitaria y Ambiental - AIDS. Gestión ambiental en EI siglo XXI. Lima, APIS, 1998.

PHILIPPI JR., A.; SILVEIRA, V. F.. Controle da Qualidade das Águas. In: PHILIPPI JR., A.. Saneamento, saúde e ambiente: fundamentos para um desenvolvimento sustentável. Barueri: Manole, 2005.

PNUD. Atlas de Desenvolvimento Humano 2003, 2003.

SABESP. Informações ETE's, 2013.

SINGLETON, H. J.. Acute toxity of effluents. Victoria: British Columbia, 1980.

VALENTIM, A. C. S.; DEZOTTI, M.. Ensaios de toxicidade. In: DEZOTTI, M.. Processos e técnicas para o controle ambiental de efluentes líquidos. Rio de Janeiro: E-papers, 2008.

VON SPERLING, M.. Introdução à qualidade das águas e ao tratamento de esgotos. Belo Horizonte: UFMG, 1996.

ZAGATTO, P. A.. Ecotoxicologia. In: ZAGATTO, P. A.; BERTOLETTI, E.. Ecotoxicologia Aquática:

Princípios e Aplicações. São Carlos: Rima, 2006. 